\title{
The Greek vs. the Cypriot guaranteed minimum income schemes: an exploratory comparative analysis
}

\author{
Varvara Lalioti $^{1}$ and Christos Koutsampelas ${ }^{2}$ \\ ${ }^{1}$ School of Social Sciences, Hellenic Open University, Patras, Greece \\ ${ }^{2}$ Department of Social and Educational Policy, University of the Peloponnese, Corinth, Greece \\ Email: blalioti@gmail.com
}

(Received 10 September 2020; revised 21 March 2021; accepted 23 March 2021)

\begin{abstract}
This exploratory paper utilises a comparative research approach to shed light upon the developmental trajectories of the Greek and Cypriot guaranteed minimum income (GMI) schemes. Our analysis indicates that, despite similarities (e.g. in the emergence of the two schemes, as part of the extensive reforms imposed during the financial crisis on the Greek and Cypriot welfare systems), there are also significant differences. These mainly relate to implementation and, ultimately, the "success" of the two schemes in attaining their declared goals. Moreover, we argue that the developmental paths followed by the Greek and Cypriot GMI schemes should be interpreted in the light of key variables ("functionalist," "political" and "institutional"), often used to explain the establishment and further evolution of such schemes. Within this context, the relatively "superior" performance of the Cypriot GMI, compared with the Greek scheme, is largely attributed to factors such as government effectiveness and political stability.
\end{abstract}

Keywords: Greece; Cyprus; guaranteed minimum income (GMI); crisis; comparative research approach; southern European welfare state model

\section{Introduction}

The aim of this exploratory paper is to compare the Greek and Cypriot guaranteed minimum income (GMI) experiences. To this end, drawing on the review of the relevant literature and data (including our own research), we shed light upon the context that led to the GMI establishment, design and implementation, and ultimately on the factors that explain the developmental trajectories of the two schemes in a comparative fashion.

In 2012, Greece, one of the few European countries and the last southern European country not to have experimented with a GMI, that is a complex means-tested social assistance scheme combining monetary and social inclusion components, adopted such a scheme. After a series of delays, it was implemented in two phases in 2014-2015 and 2016, followed by nationwide implementation in 2017. Cyprus also proceeded to abolish its old-fashioned public assistance system, in order to substitute it with a fully fledged modern GMI in 2014.

These interventions should be viewed in the light of the broad discussion about welfare state restructuring during and after the crisis (Farnsworth \& Irving, 2015, 2017) and of how large exogenous shocks can open up a window of opportunity for non-incremental policy change (Starke, Kaasch, \& Van Hooren, 2013). Additionally, these developments should be interpreted in the context of the extensive changes that took place over the same period in the so-called "southern European" welfare state model (Aguilar-Hendrickson \& Arriba González de Durana, 2020; Perez \& Matsaganis, 2019), to which both Cyprus and Greece arguably belong (Gal, 2010; Pashardes \& Koutsampelas, 2016). 
That being said, there are undoubtedly differences between the Cypriot and the Greek welfare states, such as the higher impact of the Beveridgean legacy upon the former (Shekeris, 1998), as opposed to that of the Bismarckian tradition upon the latter (Venieris, 1997). Moreover, Cyprus is argued to have influences beyond those attributed to the other "typical" southern European welfare states, such as the key role played in early welfare development by the Cypriot Trade Union and the Left movement. Furthermore, differences in welfare outcomes between Cyprus and the foregoing states include the residual and means-tested route followed by the Cypriot healthcare system for decades - which, nevertheless, was recently transformed to a universal system - or the provision of subsidised childcare (Irving, 2010).

While acknowledging the apparent limits of "clusterisation," the commonalities between the Cypriot and the Greek welfare states (and the rest of the southern European welfare universe; Ferrera, 2005) are, however, obvious. These include: the relatively low level of social expenditure ${ }^{1}$; the relative underdevelopment of minimum income protection (Matsaganis et al., 2003; Pashardes, 2009); the high reliance on families as care providers, often substituting inadequate state provisions (Gal, 2010); the low youth autonomy (as manifested in the high rates of co-residence of parents and adult children ${ }^{2}$ ); the high level of intergenerational solidarity (with parents often complementing the income of their adult children; Koutsampelas \& Pashardes, 2017) and the major role of the church in welfare provision (Gal, 2010).

Moreover, although the 2008 financial crisis was deeper in Greece, both countries experienced extensive welfare changes (Koutsampelas \& Pashardes, 2017; Matsaganis, 2020). These are reflected, inter alia, in severe cuts in social expenditure, major policy reforms, the emergence of a new balance for the intersection of state/market/family/community and a shift towards a model of solidarity, based on the interaction of institutionalised and informal solidarity. The establishment of the two GMI schemes discussed in this paper is illustrative of these changes.

Against this backdrop, we seek to add to the fast-growing analyses on minimum income protection (Bahle, Hubl, \& Pfeifer, 2011; Marx \& Nelson, 2013), including the most recent contributions, which build on the definition of the main dimensions of variation of the relevant schemes, so as to introduce new typologies (Natili, 2020); as well as to studies discussing the development of minimum income standards (Deeming, 2017, 2020). More specifically, we draw on a major part of the bibliography highlighting the role of a diverse range of variables in shaping GMI developmental trajectories including the political process leading to GMI reforms and the differentiated policy outcomes of these schemes (Jessoula et al., 2014; Natili et al., 2019; Noël, 2019).

Hence, we underscore the explanatory value, in terms of both policy reform and implementation, of three broad "families" of variables. These are at the centre of comparative social policy analysis, often with a focus on minimum income schemes (Lalioti, 2020): "functionalist" variables, underlining the salience of "functional" pressures, that is "objective" challenges and pressures for reform (e.g. high poverty rates or economic constraints), which may emerge from wider socio-economic changes; "political" variables, based on the acknowledgement that "politics matters"; and "institutional" variables, stressing the importance of state apparatus and administrative structures.

"Functionalist" arguments have been largely replaced by "political" and "institutional" arguments, but the effects of "problem pressure" dynamics remain acknowledged, especially in light of the recent economic recession (Van Kersbergen \& Vis, 2014, pp. 5, 10-12). Political arguments often emphasise the effects of partisanship, the dynamics of political competition, political exchange between social actors and political parties, as well as the importance of coalitions (Lalioti, 2016a; Natili, 2018; Natili et al., 2019).

That being said, our analysis also seeks to stress the interpretive salience of additional variables of "political" nature, i.e. "political stability." This is a variable mostly taken into account with regard to economic development and, more rarely, in the welfare state literature, wherein political stability is one of the outcomes of effective social protection (Svensson, Urinboyev, \& Åström, 2012).

\footnotetext{
${ }^{1}$ Based on Eurostat data for 2017, Greece and Cyprus spent, respectively, 25.2 and 18.5 per cent of their GDP (EU-28: 27.8 per cent).

${ }^{2}$ In 2018, the share of young adults (18-34) living with their parents was 68.1 per cent in Greece and 57.1 per cent in Cyprus (EU-27: 48.2 per cent; Eurostat Online Database, code: ilc_lvps08).
} 
Yet, "political stability," often perceived, among other things, as governmental longevity/duration (see e.g. Hurwitz, 1973 for an early elaboration on the concept), may also function as a tool that helps us understand differences in welfare policy trajectories and outcomes. Finally, institutional arguments underline the importance of factors, such as state efficiency and the type of the bureaucratic model adopted (Sotiropoulos, 2004).

Although the above sets of variables are used to analyse different reform outputs (Jessoula et al., 2014; Van Kersbergen \& Vis, 2014), they are likewise useful in explaining differences in policy effectiveness. An example may be found in the view that limited state efficiency and low levels of professionalisation within domestic bureaucracies pose obstacles to the GMI implementation in southern Europe (Madama, 2010). This argument implies that administration in the region suffers from a low capacity for implementation.

To outline a concrete example, the administrative ability to accurately assess recipients' needs and income has been considered a typical weakness in southern Europe (Atkinson, 1998; Ferrera, 2005, pp. 7-11). This, in turn, means that the competent authorities in these countries are less able to determine the actual eligibility for benefits, resulting to targeting errors and lower policy effectiveness.

Similarly, the distribution of power in the policy arena and the commitment and cooperation of the actors involved in policy design and implementation are regarded as key drivers of policy effectiveness (World Bank, 2017). These parameters should be viewed in conjunction with studies stressing the salience of functional pressures, as exemplified by the impact of "need" on policy effectiveness (Cerna, 2013).

Within this context, we argue that, despite similarities - such as the role of "Memoranda of Understanding" in motivating the GMI reforms or the existence of common features in the design of the two schemes - there are significant differences. These mostly regard implementation and, ultimately, the "success" of the two schemes in achieving their declared goals.

It is also important to underscore that, while policy design and implementation are conceptually distinct, in practice, they may overlap or be interrelated. Although the design phase is about determining the problem, the goals and the most appropriate instruments, policymakers often incorporate their considerations and expectations into policy design. For example, in a country such as Greece, where authorities face difficulties to validate citizens' declared income, policymakers may be reluctant to overrely on income-related eligibility criteria, even if they believe in their desirability. On that basis, disentangling the net effects of design and implementation on policy outcomes is a challenging research endeavour (Pal, 2014).

Furthermore, we argue that, while in both countries, functional pressures, such as rising unemployment and poverty, played a key role in the GMI emergence, the better performance of the Cypriot scheme is largely associated with "superiority" in areas, such as government effectiveness and political stability. These remarks also point towards major and structural differences between the Greek and Cypriot political and administrative systems.

Next, the main body of the paper is divided into two sections: the first essentially compares the two schemes in terms of context, design and implementation. The second explains their developmental trajectories by exploring the effect of different variables. The concluding section summarises our findings.

\section{The Greek vs. the Cypriot GMI}

\section{The Greek case}

\section{Context}

Although the first parliamentary proposal for a welfare mechanism similar to a GMI was submitted to the Greek Parliament in 1998, the establishment of a national GMI, more than a decade later, was part of the country's Memorandum of Understanding. After years of ambivalence, indifference and/or overt hostility against a GMI, the medium-term $2013-2016^{3}$ fiscal strategy explicitly referred to the design and implementation of the scheme (Matsaganis, 2020).

\footnotetext{
${ }^{3}$ Law 4093/2012, IA.3.
} 
This shift should be viewed in the light of the severe implications of the financial crisis and the related austerity policies. Greece was going through its fifth consecutive year of recession, a large proportion of the population was experiencing a dramatic decline in living standards and major political changes were taking place, such as the move from single-party governments to more pluralistic arrangements, demanding new alliances. Measures to tackle poverty and social exclusion also became increasingly important for electoral purposes (Lalioti, 2016a; see also Jessoula \& Natili, 2020 on the salience of a "political demand and supply" analytical framework, as a means to explain reform).

Against this backdrop, a ministerial decision ${ }^{4}$ allocated $€ 20$ million for a 6-month GMI pilot (in 2015, and in 13 municipalities). This was followed by two phases of implementation: one in 30 municipalities (between 14 July 2016 and 31 December 2016) and nationwide in 2017.

\section{Design}

The Greek GMI is financed by general taxation and includes three pillars: income support, access to social services and goods and labour market integration/re-integration measures. ${ }^{5}$ The scheme aims to guarantee that all eligible persons receive a specified income, assumed to ensure a minimum accepted standard of living. Implementing the GMI is a responsibility of national authorities, such as the Ministry of Labour and Social Affairs, in collaboration with local governments and agencies.

Although the Greek GMI seeks to reach the so-called "extreme poor," population groups such as undocumented migrants are uncovered. Eligible individuals/families must meet criteria for residence, income and assets, while failure to conform to rules (e.g. attending a "second-chance school," in the case of beneficiaries aged over 45 who have not completed compulsory education) leads to loss of access.

The GMI varies according to the number and age of the household members: the maximum monthly income support is $€ 200$ for single-adult households, increasing by $€ 100$ per adult and $€ 50$ per child. The first dependent child in a single-parent family is compensated at the adult rate. ${ }^{6}$ Housing costs are not considered, but there are provisions for families with disabled members or single-parent families. The maximum guaranteed amount cannot exceed $€ 900$ monthly, irrespectively of household composition.

Examples of GMI-related social services are individualised consultancy and social grocery services. Labour market integration/re-integration measures, implemented by the Manpower Employment Organisation and other agencies, target beneficiaries who belong to the active population, are capable of working and less than 67 years old.

The GMI "architecture" remained relatively stable over the three implementation phases. Among the small changes adopted are changes in the time period used in calculating the GMI amount, redefining the claiming unit at the household level rather than at the family level, as well as actions aiming at enforcing the GMI social integration component (although work-related conditionalities are essentially absent).

Additionally, in December 2019, a few months after the new (conservative) New Democracy (ND) government came to power, succeeding the coalition government between the left ["Coalition of the Radical Left" (SYRIZA)] and the nationalist right ["Independent Greeks" (ANEL)], the scheme was renamed: from "social solidarity income" to "GMI." This change should be viewed alongside the recent constitutional amendment, which referred to the obligation of ensuring a minimum income to all citizens.

Overall, the main weaknesses in the design of the scheme regard the low level of the monetary allowance, the exclusion of certain population groups and inherent problems stemming from the largely centralised system of governance in the country, including the lack of resources, which would have allowed municipalities to tackle the task more effectively at the local level. In the course of the different

\footnotetext{
${ }^{4}$ No. 39892/ГА 1.2., 7 November 2014.

${ }^{5}$ This subsection largely draws on (Lalioti, 2016a, 2016b).

${ }^{6}$ See Ministerial Decision No. $\Delta 13 /$ o1א./33475/1935, 15 June 2018.

${ }^{7}$ See the speech of the President of the Greek Parliament (19 November 2019) and the ratification of the 2020 State Budget (https://www.hellenicparliament.gr/), as well as Law 4659/2020.
} 
phases, the design of the scheme, as exemplified by the upgrade in the platform developed at the ministry's information centre, appears to have improved (Matsaganis, 2020, pp. 593-595).

\section{Implementation}

The GMI implementation has been assessed by the National Institute of Labour and Human Resources and the World Bank. The former mainly utilised quantitative methodological tools to evaluate the GMI pilot (Gavroglou, 2015), while the latter used mostly qualitative tools (World Bank, 2015), as opposed to the $2019^{8}$ study of the institution, which focused on the implementation during the first two years of the scheme, based on quantitative data.

These evaluative efforts largely focused on administrative aspects of the GMI, highlighting issues jeopardising implementation. These included understaffing and the limited administrative capacity of the municipal agencies, problems in cross-checking and data verification, and the lack of systematic monitoring of indicators; and should be seen alongside the delay in the implementation of all three phases of the scheme (Lalioti, 2016b).

The GMI effect on poverty alleviation was mainly discussed in the second World Bank study, which concluded that the scheme was a significant source of income for poor households, also reducing income inequality and the poverty gap. However, its impact on the incidence of poverty was marginal and only evident when adopting "extreme" relative poverty lines. ${ }^{9}$ The study also revealed a low take-up rate, underlining the need for more outreach efforts.

The above corroborate findings by independent researchers, according to which the Greek GMI provided income support far below the poverty threshold, only reducing acute poverty (Ziomas, Capella, \& Konstantinidou, 2017). In a similar vein, Sakellaropoulos, Lalioti and Kourachanis (2019) find that a large proportion of beneficiaries continued to rely on the survival strategies they used before the GMI (i.e. relying mostly on help from their families). This was partly attributed to the inadequacy of the benefit and the uneven development of the three pillars; especially of the "reintegrating able recipients to the labour market" pillar, but also, although to a lesser extent, of the "linking income support to complementary services" pillar.

Overall, the problems identified were largely problems of "administrative" nature and should be viewed alongside the rather low capacity - if not the unwillingness - of the government to provide logistical support and leadership to the municipalities involved in implementation. Cooperation between different ministries proved likewise difficult. Furthermore, the failure to tie cash assistance with social services and activation programmes had far-reaching implications, such as raising the risk of granting assistance to households with higher, but unreported incomes (Matsaganis, 2020).

\section{The Cypriot case}

\section{Context}

In 2014, Cyprus introduced a GMI scheme, replacing the old sui generis Public Assistance system, wherein discretionary payments were based, inter alia, on household means and the existence of liable relatives (Irving, 2010, p. 233). Although the system proved indispensable (e.g. for coping with the urgent social needs, following the dramatic events of the 1974 Turkish invasion), it had many drawbacks, such as the exclusion of the working poor, a wide scope for discretionary payments, imperfect targeting and the absence of effective activation support (Pashardes, 2009; Pashardes \& Polycarpou, 2011).

Hence, it was decided that, instead of modifying the old system, a completely new system, with different logic and novel characteristics, should be introduced. The related reform was included in the prerequisites of the Memorandum of Understanding and was presented as a means to address the shortcomings of the old system and improve social protection. The new scheme was rapidly designed and

\footnotetext{
${ }^{8}$ In collaboration with KAPA Research, a survey firm.

${ }^{9}$ Extreme relative poverty is set at 40 per cent of the median of the equivalised income.
} 
came into effect via the 2014 GMI and Social Benefits Law, ${ }^{10}$ according to which all legal residents had the right to enjoy a minimum acceptable standard of living.

\section{Design}

The scheme consists of three pillars: income support, access to services and activation. The first pillar is based on a monthly cash benefit, defined as the difference between the actual income of the recipient unit and a pre-specified basic amount, corresponding to the minimum standard of living accepted by society.

The level of basic amount is calculated using reference budget methodology and varies depending on the size and age structure of the recipient unit. In 2014, the basic amount was set at $€ 480$ monthly (single person), increasing by 50 per cent for each additional adult and by 30 per cent for each additional child. The family income is the sum of the actual incomes of all members, with certain incomes being partially or completely exempted. Only a proportion of employment income is considered, so as to preserve beneficiaries' work incentive. Additionally, recipients living in a rented apartment or making mortgage payments are entitled to a housing allowance on top of the basic amount.

Eligibility is determined on the basis of age, nationality, residency, employment status and the financial assets of the recipient. Beneficiaries must also satisfy a number of job-related conditionalities, such as registering with the Public Employment Service and accepting "suitable" jobs. Not conforming to these conditionalities endangers eligibility.

The second and third pillars provide access to subsidised or free-of-charge services, necessary for preventing material deprivation and activating recipients. These include healthcare, psychological and career advice services, educational and vocational programmes as well as, in the case of recipients with dependents, subsidised child and long-term care (Koutsampelas, 2016).

Overall, the Cypriot GMI is characterised by a modern and relatively comprehensive design, providing, in principle, holistic protection with rather few apparent weaknesses, the most important being the limited coverage of certain groups, which might be at risk of high poverty (see also Table 1).

\section{Implementation}

Although the speed of implementation might have been arguably affected by the experience of the Cypriot public services with the Public Assistance system, the abrupt rise in unemployment further expedited developments (Koutsampelas, 2016). Fast implementation came nevertheless at the cost of complaints from several stakeholders who were not given adequate time to effectively participate in the consultation process and contribute to the design of the scheme (Soumeli, 2014).

Moreover, in order to guarantee the smooth transition from the old system to the GMI, the former system was only gradually phased out. Hence, for a period of time, both schemes were working in parallel, with Public Assistance recipients steadily reducing. This approach minimised the possibility of uncovered recipients due to the change of the system.

Another novelty of the reform was the development, for the first time, of a computerised Social Benefit Register that collected information about the persons receiving state benefits (Stylianides, 2019). This crucial upgrade of the technological infrastructure corrected a major weakness of the previous system, in the context of which many social welfare benefits were provided independently and without the exchange of information between the various governmental compartments (Pashardes, 2009); thereby improving the effectiveness of the new scheme (Stylianides, 2019).

In parallel, the "teething problems" of the GMI were quickly corrected through small-scale legislative interventions. Examples of such interventions included a legislative modification, ${ }^{11}$ providing the Minister of Labour with discretionary power to grant eligibility to special cases of applicants, even if they failed to satisfy the formal eligibility criteria; as well as a subsequent amendment ${ }^{12}$ of similar logic,

\footnotetext{
${ }^{10}$ Law $109(\mathrm{I}) / 2014$.

${ }^{11} 3$ (I)/2015 modification of Law 109(I)/2014.

${ }^{12} 118$ (I) 2015 modification of Law 109(I)/2014.
} 
offering high-ranked officials the capacity to award eligibility to persons facing "extraordinary personal circumstances." These legislative modifications improved the inclusivity of the scheme.

Furthermore, after taking into account the large number of households that had experienced significant income reductions during the crisis, while also possessing immovable property that made them ineligible for the GMI support, the government relaxed the asset criteria for access to the scheme (Pashardes \& Koutsampelas, 2015). This modification improved its coverage, while also encountering public criticism regarding the strictness of the eligibility criteria.

The greatest concern, however, was the scheme's impact on poverty alleviation. In 2013, the ex-ante impact assessment of the GMI, conducted by the University of Cyprus, in collaboration with the International Labour Organization (ILO) and the Ministry of Labour, indicated that the new scheme was clearly more effective and comprehensive than the previous system. Assuming full take-up, the simulations showed that the GMI had the potential to almost eliminate absolute poverty, while significantly reducing relative poverty (Pashardes, Koutsampelas, \& Polycarpou, 2013). A subsequent micro-simulation exercises verified these results (Pashardes \& Koutsampelas, 2016; see also European Commission, 2019).

Critics of the GMI argued, however, that the scheme did not eradicate every form of deprivation, as exemplified by the fact that beneficiaries still faced nutritional risks, which intensified in the case of multi-member families (Chrysostomou \& Andreou, 2017). Additional criticism concerned rising housing costs, triggering the government to upgrade the GMI-related housing allowance (Koutsampelas, Andreou, \& Tsolaki, 2019). Finally, despite the absence of quantitative data on the GMI performance concerning the labour market integration/re-integration of recipients, the lack of specialised personnel to support recipients and the harsh labour market conditions in the aftermath of the financial crisis seem to have enhanced the relative ineffectiveness of the activation component (Christofides \& Koutsampelas, 2019).

Several other minor implementation issues (e.g. delays in processing applications and disbursing payments), as well as minor faults in the GMI design (e.g. the complexity of some administrative processes; Council of Europe: Commissioner for Human Rights, 2016; European Commission, 2017), were rapidly corrected, without causing any long-term consequences in the performance of the system. Hence, although the implementation of the Cypriot GMI was not entirely smooth, the problems faced in Cyprus were arguably less extensive and more rapidly encountered than in the Greek case.

\section{Comparison of the Greek and Cypriot GMI}

The comparison of the two schemes reveals many commonalities. These regard mainly the GMI context and design, and less so implementation - including the outcomes achieved, based on the policy reports and studies assessing each scheme independently and reviewed in more detail in the previous sections (for Greece: Sakellaropoulos, Lalioti, \& Kourachanis, 2019; World Bank, 2015, 2019; Ziomas, Capella \& Konstantinidou, 2017; and for Cyprus: European Commission, 2019; Pashardes \& Koutsampelas, 2016; Pashardes, Koutsampelas, \& Polycarpou, 2013).

While in both cases the GMI was established under circumstances of acute crisis and was in line with Memorandum obligations, similarities in design include, inter alia, the following: both are noncategorical national schemes, offering, in principle, relatively comprehensive coverage (although there are certain population groups, who are either explicitly excluded, such as undocumented migrants, or partly covered); both consider the size and age structure of the recipient unit in benefit determination, using a similar approach; in both schemes the duration of entitlement is unlimited - insofar as beneficiaries continue to satisfy eligibility conditions; and in both schemes entitlements are linked to sanctions (i.e. loss of entitlement, if beneficiaries do not satisfy certain conditionalities).

Differences, such as taking account of housing costs and providing limited discretionary powers to officers in the case of the Cypriot GMI, as opposed to excluding such costs and the reliance on a more strictly rule-based system in the Greek case, are certainly less than similarities. Furthermore, the Cypriot GMI is characterised by a rather strict age restriction, since the applicant must be at least 28 years old. 
However, this restriction relaxes for certain categories (e.g. married, single persons, persons with disabilities and others). Finally, the Cypriot GMI utilises a combination of "financial," "demanding" and "enabling" elements, in a more balanced way, compared to the Greek GMI.

Table 1, largely benefiting from the GMI dimensions highlighted in works on the categorisation of similar schemes (Marlier \& Frazer, 2016; Natili, 2020), seeks to provide a concise but comprehensive picture of the "architecture" of the two schemes.

When implementation and outcomes are considered, the divergence between the two schemes becomes more pronounced. Illustrative of this divergence is the rapid implementation of the Cypriot GMI compared to the Greek GMI, or the greater effectiveness of the former in improving the living conditions of beneficiaries, as this is reflected in "basic" outcomes, such as coverage, adequacy, poverty impact and take-up.

For example, taking into account the importance of the ratio of actual beneficiaries to the total number of persons living in poverty or severe poverty as an indicator of the relative diffusion of the GMIrelated benefits (and thereby of their inclusiveness; Natili, 2020), the available data shows a clear superiority of the Cypriot scheme ( $2.38 \mathrm{CY}$ vs. $0.71 \mathrm{GR})$ for severe poverty and a better performance

Table 1. Comparison of the "architecture" of the Greek and Cypriot GMI schemes.

\begin{tabular}{|c|c|c|}
\hline Characteristic & What is the practice in Greece? & What is the practice in Cyprus? \\
\hline Governance & $\begin{array}{l}\text { At the national level, but with } \\
\text { regional elements }\end{array}$ & At the national level \\
\hline Population coverage & Non-categorical scheme & Non-categorical scheme \\
\hline Benefit calculation & $\begin{array}{l}\text { Level of benefit is defined using a } \\
\text { method which considers } \\
\text { household composition }\end{array}$ & $\begin{array}{l}\text { Basic amount is calculated using budget reference } \\
\text { methods, with the amount increasing according to } \\
\text { OECD equivalence scales }\end{array}$ \\
\hline Level of the benefit & $\begin{array}{l}€ 200 \text { for a single adult; }+€ 100 \text { per } \\
\text { additional adult; }+€ 50 \text { per } \\
\text { additional child }\end{array}$ & $\begin{array}{l}€ 480 \text { for a single adult; }+50 \% \text { per additional adult; } \\
+30 \% \text { per additional child. }\end{array}$ \\
\hline Housing costs & Excluded & Considered \\
\hline Payment duration & Unlimited & Unlimited \\
\hline $\begin{array}{l}\text { Discretionary power of } \\
\text { officials }\end{array}$ & None & Limited \\
\hline \multicolumn{3}{|l|}{ Activation strategy: } \\
\hline (a) Financial elements & Earnings disregard & Earnings disregard \\
\hline $\begin{array}{l}\text { (b) Demanding } \\
\text { elements }\end{array}$ & $\begin{array}{l}\text { Sanctions (e.g. loss of access in } \\
\text { case of not conforming with } \\
\text { certain requirements) }\end{array}$ & $\begin{array}{l}\text { Sanctions (e.g. loss of access in case of not } \\
\text { conforming with job-related conditionalities) }\end{array}$ \\
\hline (c) Enabling elements & $\begin{array}{l}\text { Access to labour market integration } \\
\text { programmes }\end{array}$ & $\begin{array}{l}\text { Training and vocational programmes; access to } \\
\text { services; counselling }\end{array}$ \\
\hline Working poor coverage & Yes & Yes \\
\hline Age limits for eligibility & None & Very high (28+; with exceptions) \\
\hline $\begin{array}{l}\text { Population groups with } \\
\text { limited, insufficient or } \\
\text { no coverage }\end{array}$ & Undocumented migrants & $\begin{array}{l}\text { Asylum seekers, }{ }^{a} \text { undocumented migrants and } \\
\text { third country nationals }{ }^{b}\end{array}$ \\
\hline
\end{tabular}

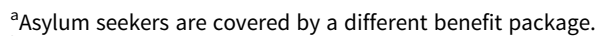

${ }^{\mathrm{b}}$ Third-country nationals are eligible if they fulfil residence-related criteria.
} 
for poverty (0.41 CY vs. 0.32 GR; see Table A1, Appendix). Following Nelson's (2013) definition of minimum income adequacy, ${ }^{13}$ the Cypriot scheme is also more adequate than the Greek scheme (40 vs. 31.5) for a single adult (with similar differences emerging for larger recipient units; see Table A2, Appendix).

In terms of poverty alleviation, although there is not a single study comparing their anti-poverty performance based on the same methodology, the policy reports and studies assessing each scheme independently allow us to deduce the higher performance of the Cypriot scheme. Furthermore, despite the scant available information on take-up, with only one study reporting low take-up for the Greek case (World Bank, 2019) and no relevant analysis for the Cypriot case, the relatively high coverage rate of the latter may be regarded as an implicit evidence of a satisfactory take-up rate.

Table 2 summarises the observed differences in coverage, adequacy, poverty impact and take-up.

Table 2. Comparison of "basic" GMI-related outcomes in Greece and Cyprus.

\begin{tabular}{lll}
\hline & Greece & Cyprus \\
\hline Coverage & Medium & High \\
\hline Adequacy & Low & Medium \\
\hline Poverty impact: & & Low \\
\hline Relative poverty & Negligible & High \\
\hline Absolute poverty & Medium & Medium to high \\
\hline Poverty intensity & Medium & - \\
\hline Take-up & Low & \\
\hline
\end{tabular}

Finally, another dimension, relevant to the assessment of the outcomes from the implementation of the GMI, but not included in Table 2, due to the complete lack of quantitative evidence, is the capacity of the two schemes to activate beneficiaries. That being said, it can be argued that their activation component seems to be the Achilles heel of both programmes.

Yet, some emphasis is being placed by the Cypriot scheme on work-related conditionalities and employment programmes, arguably a sign of a stronger commitment to labour market integration. On the contrary, the Greek GMI is relatively "silent" on this matter.

\section{Possible explanations for the developmental paths followed by each scheme}

\section{Functionalist factors as explanatory variables}

After 2009, both countries experienced deep recessions, which severely affected the observed levels of unemployment and poverty. The data presented in Table 3 is revealing.

In Greece, the unemployment rate increased by 19.7 percentage points between 2008 and 2013. Thereafter, it subsided, remaining, however, at unacceptably high levels. Cyprus had one of the lowest unemployment rates in Europe in 2008, but the recession catapulted unemployment at 15.9 per cent in 2013. Increases in long-term unemployment were likewise striking in both countries.

Poverty and social exclusion also soared. The "at risk of poverty" indicator peaked at 23.1 per cent in 2013 and at 16.2 per cent in 2015 in Greece and Cyprus, respectively. Furthermore, the "at risk of poverty or social exclusion" (AROPE) indicator reveals that, during 2011-2015, one out of three

\footnotetext{
${ }^{13}$ The value of the benefit for a particular household, divided by the median equivalised income, times 100.
} 
Table 3. Main social and labour market indicators in Greece and Cyprus (2008-2015).

\begin{tabular}{|c|c|c|c|c|c|c|c|c|c|}
\hline & & 2008 & 2009 & 2010 & 2011 & 2012 & 2013 & 2014 & 2015 \\
\hline \multirow[t]{2}{*}{ Unemployment } & GR & 7.8 & 9.6 & 12.7 & 17.9 & 24.5 & 27.5 & 26.5 & 24.9 \\
\hline & $\mathrm{CY}$ & 3.7 & 5.4 & 6.3 & 7.9 & 11.9 & 15.9 & 16.1 & 15 \\
\hline \multirow[t]{2}{*}{ Long-term unemployment } & GR & 3.7 & 3.9 & 5.7 & 8.8 & 14.5 & 18.5 & 19.5 & 18.2 \\
\hline & $\mathrm{CY}$ & 0.5 & 0.6 & 1.3 & 1.6 & 3.6 & 6.1 & 7.7 & 6.8 \\
\hline \multirow[t]{2}{*}{ AROP } & GR & 20.1 & 19.7 & 20.1 & 21.4 & 23.1 & 23.1 & 22.1 & 21.4 \\
\hline & $\mathrm{CY}$ & 15.9 & 15.8 & 15.6 & 14.8 & 14.7 & 15.3 & 14.4 & 16.2 \\
\hline \multirow[t]{2}{*}{ AROPE } & $\mathrm{GR}$ & 28.1 & 27.6 & 27.7 & 31 & 34.6 & 35.7 & 36 & 35.7 \\
\hline & $\mathrm{CY}$ & 23.3 & 23.5 & 24.6 & 24.6 & 27.1 & 27.8 & 27.4 & 28.9 \\
\hline \multirow[t]{2}{*}{ Severe material deprivation } & GR & 11.2 & 11 & 11.6 & 15.2 & 19.5 & 20.3 & 21.5 & 22.2 \\
\hline & $\mathrm{CY}$ & 9.1 & 9.5 & 11.2 & 11.7 & 15 & 16.1 & 15.3 & 15.4 \\
\hline \multirow[t]{2}{*}{ Public debt (\% GDP) } & GR & 109.4 & 126.7 & 146.2 & 172.1 & 159.6 & 177.4 & 178.9 & 176 \\
\hline & $\mathrm{CY}$ & 45.6 & 54.3 & 56.4 & 66 & 80.3 & 104 & 109.2 & 107 \\
\hline
\end{tabular}

Abbreviations: AROP, at risk of poverty; AROPE, at risk of poverty or social exclusion.

Source: Eurostat.

citizens in Greece faced a risk of poverty or social exclusion. Cyprus likewise suffered from high AROPE rates.

The "severe material deprivation" rate almost doubled in Greece and increased substantially in Cyprus between 2008 and 2015. In parallel, both countries experienced acute fiscal pressures, reflected in rising public debt.

Overall, in Greece, since many unemployed gradually lost access to contributory unemployment benefits (and were therefore left completely unprotected from poverty), the lack of minimum income support further exacerbated social problems. Similarly, in Cyprus, the existing Public Assistance system proved inadequate to cover the increasing number of working poor and long-term unemployed.

Hence, as thousands of families found themselves at risk of poverty the extensive functional pressures increased the demand for minimum income protection. While these pressures created an urge to seriously upgrade income protection for the poor, the rapidity, the effectiveness and the shape of the reforms were influenced by other factors, too.

\section{Political factors as explanatory variables}

\section{Greece}

The traditional power resources argument, associating leftist cabinets and trade unions with higher "vertical redistribution" (Häusermann, Picot, \& Geering, 2013), cannot explain the Greek GMI developmental history. After years of procrastination, due to divisions across the governing parties about the scheme, its eventual establishment is linked to the building of a pro-GMI coalition among ND, "Panhellenic Socialist Movement" (PASOK) and "Democratic Left" (DIMAR); i.e. the members of the three-party coalition government in June 2012. Within a context that increased the political attractiveness of non-contributory benefits and austerity-related implications for the mostly insurance-based Greek welfare system, this alliance was further boosted by the weakening of the trade unions, which often expressed hesitance, if not hostility, towards the GMI (Lalioti, 2016a).

Yet, the fragility of the alliance, as reflected in DIMAR's withdrawal from the government in June 2013 and the essential absence of actors playing key roles in the GMI debate in other countries (e.g. religious organisations), undermined the "success" or even the continuation of the scheme. An 
example is found in delays in implementation, following the rise to power of the SYRIZA-ANEL coalition in January 2015, which expressed scepticism about the scheme.

While political consensus made therefore possible the Greek GMI, partisan change, and more specifically the ideological hostility of the new government towards a scheme "imposed" by supranational actors (Matsaganis, 2020, p. 594), jeopardised the continuity and the implementation of the GMI.

\section{Cyprus}

In Cyprus, the GMI law was passed in July 2014, approximately one year after the election of centre-right President Anastasiades. The 34 votes in favour came from members of parliament (MPs) of the centreright "Democratic Rally" (DISY), the centrist "Democratic Party" (DIKO), the centre-left "Movement for Social Democracy" (EDEK) and the conservative "European Party" (EVROKO). There were 20 abstentions from MPs of the left-wing "Progressive Party of Working People" (AKEL) and the centrist "Citizens' Alliance."

While the GMI had support across the political spectrum, the reactions of the trade unions were rather critical. Focusing on issues of adequacy and inclusiveness, the intensity of the reactions of the trade union movement depended on their political allegiances (Satsias, 2014). Yet, the GMI introduction enjoyed a relatively broad political consensus.

In contrast, however, to what happened in Greece, the lack of partisan change, as reflected in President Anastasiades' re-election in 2018, safeguarded the GMI from delays and/or discontinuity. Broadly speaking, the likelihood that a government will not be destabilised is widely associated with effective policy implementation, whereas an unstable political environment shortens governments' policy horizons, leading to suboptimal policy choices (Aisen \& Veiga, 2011).

Hence, the above should be viewed in conjunction with the higher stability of the Cypriot political system $v i s-\grave{a}$-vis the Greek system, largely reflected in citizens' perceptions of "political stability" in the two countries. Figure 1 confirms that the level of perceived political stability in Greece during the crisis differed substantially from that in Cyprus.

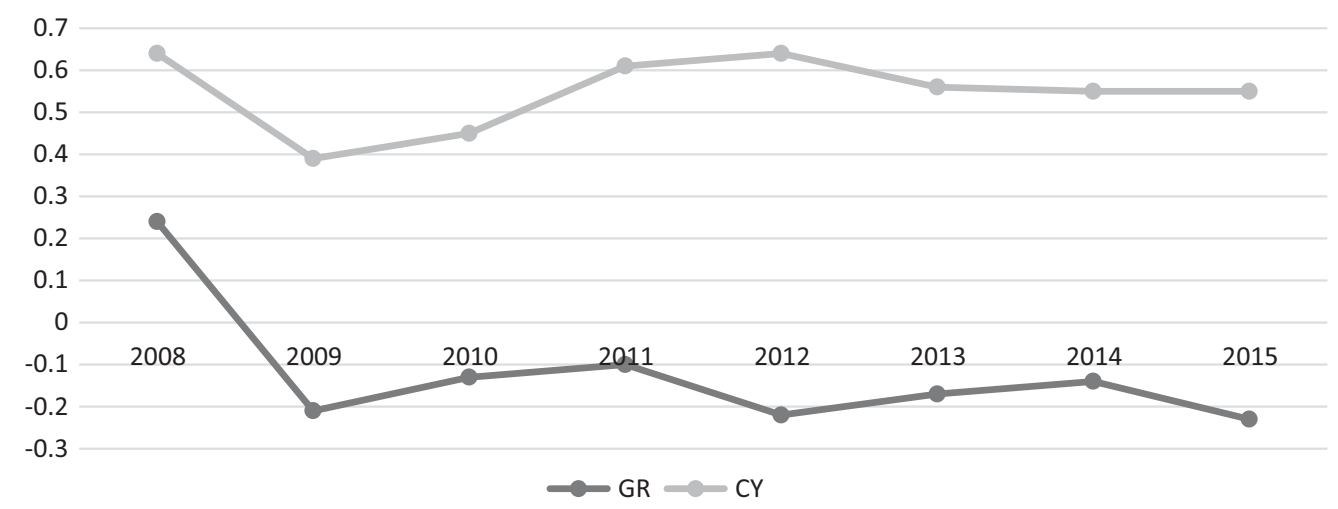

Figure 1. Political stability in Greece and Cyprus (2008-2015).

Source: Political Stability and Absence of Violence/Terrorism Indicator, Worldwide Governance Indicators.

Also considering that, historically, the Cypriot political system exhibits at least a certain degree of solidarity in issues regarded as "socially important," Cyprus arguably provided firmer ground for the uninterrupted implementation of the GMI. This feature may be additionally attributed to the small island state status of Cyprus. Despite idiosyncrasies, which have stunted democratic development of the state welfare for decades, the foregoing status appears to have encouraged consensus over social policies (Irving, 2010). 
Furthermore, while the tough measures taken by successive Greek governments during the crisis compounded the relative instability of the Greek case, the reactions to the similar policies imposed in Cyprus were less intense, so did not threaten stability (Koutsampelas \& Pashardes, 2017). Once again, the small island society of Cyprus may be associated with rather high levels of socio-political tolerance (Dommen, 1980).

\section{Institutional factors as explanatory variables}

The possibility of partisan change and, overall, the degree of political stability are also partly related to the different types of governance in Greece and Cyprus, and therefore to the differences between parliamentary and presidential government. Specifically, in contrast to the higher possibility of government change and interruptions in national policymaking in the Greek parliamentary system, the presidential system in Cyprus appears to ensure a relative continuity in policymaking and a higher degree of political stability.

It is possible that the president may lack the necessary parliamentary support to pass the implementation of difficult reforms. The recent history has shown, nevertheless, that the Cypriot political system has the necessary maturity of building consensus on matters of importance (Rapanos \& Kaplanoglou, 2014).

The literature on institutional variables as means to interpret policy reform and implementation mainly stresses, however, the importance of a well-functioning public sector, as well as the high degree of administrative capability required for targeted provisions (Ferrera, 2005). To this end, we compare government effectiveness in Greece and Cyprus (Figure 2).

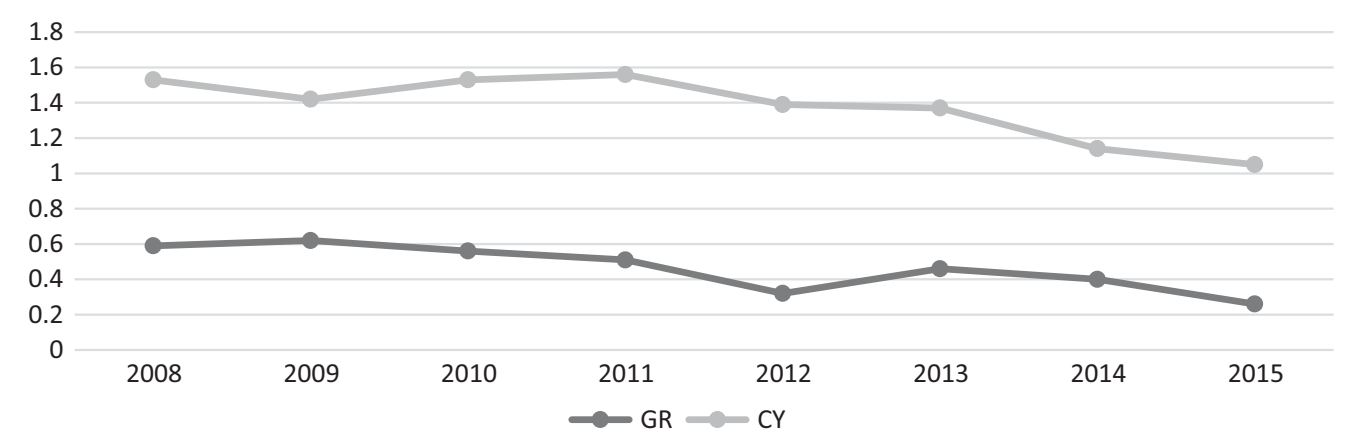

Figure 2. Government effectiveness in Greece and Cyprus (2008-2015).

Source: Government Effectiveness Indicator, Worldwide Governance Indicators.

The data reflects perceptions of the quality of public/civil services, the degree of independence from political pressures, the quality of policy formulation and implementation and the credibility of government commitment to policies. During the reference period, the WGI index for Cyprus was significantly higher than that for Greece. Although for both countries the index deteriorated after 2008, the Greek performance remained significantly inferior to that of Cyprus. This outcome may be attributed to the different legacies of the "Beveridgean" and "Bismarckian" traditions linked to the Cypriot and the Greek administrative systems, respectively.

In the former, administration applies indirect control with administrative heads not disclosing or being affiliated with political parties, while in the latter government and political parties are directly involved in administration, encouraging phenomena of corruption. Furthermore, the luck of trust towards the Greek public administration might explain the choice of a strictly rights-based GMI, as opposed to the adoption of some discretionary elements in Cyprus, which provide a degree of flexibility to officials. 


\section{Conclusions}

This exploratory paper utilises a comparative research approach to shed light upon the Greek and Cypriot GMI experiences. We discuss the context that led to the establishment of the two schemes, as well as their design and implementation, while also offering a comparison of the schemes and an explanatory framework for the developmental trajectories followed by them.

Our analysis reveals many similarities, such as the establishment of the GMI as part of the Memorandum obligations of both countries and common features in design (e.g. eligibility conditions and payment duration). Yet, there are also significant differences in implementation and outcomes and, consequently, in the ultimate "success" of the two schemes in attaining their goals. For instance, the Cypriot GMI is more effective in combating poverty and more efficient in targeting, while the Greek system is marred by low levels of take-up and other inefficiencies of administrative nature.

Furthermore, we argue that the developmental paths of the two schemes may be largely understood in the light of key variables (i.e. functionalist, political and institutional), often utilised to explain the emergence and evolution of GMI schemes. In both countries, functional pressures, such as high unemployment and poverty, created a context that encouraged demand for a GMI.

However, the higher Cypriot performance is linked to the relative "superiority" of the Cypriot case in terms of government effectiveness and political stability. In regard to the former, the Greek case seems, inter alia, to be more in line with the thesis that the relatively meagre development of GMI schemes in southern Europe is largely attributed to weak administrative capacity (Ferrera, 2005; Madama, 2010). In regard to the latter, the relative stability of the presidential system in Cyprus seems to have offered a firmer ground for the rapid implementation of such an important reform; in contrast to Greece, where the political turmoil, following three very unpopular economic adjustment programmes managed by four consecutive governments during nine years (2010-2019), did the exact opposite.

Moreover, building upon our analysis of the two schemes, their comparison may yield fruitful interpretations regarding, first, the concept of "path dependence," but also those of policy change and convergence. Studies of path dependence have hypothesised that the welfare state has a relatively small potential for change (Hinrichs, 2000). The literature on convergence, on the other hand, focuses on welfare state changes, through which a degree of standardisation is expected to emerge (Adnett \& Hardy, 2005).

The evolutionary paths followed by the examined schemes indicate that, while the initial design is a determinant in consolidating specific policy outcomes, a potential for change cannot be excluded. In that sense, change can be understood in the context of the new "welfare landscape" that emerged in southern Europe during the years of the recent recession. Although the "weight" of means-tested and contributory benefits in southern European countries remains quite different, one of the main features characterising the reforms taking place these years is the extension of income maintenance support in the region, beyond the scope of traditional contributory social insurance programmes (Aguilar-Hendrickson \& Arriba González de Durana, 2020; Jessoula \& Natili, 2020; Matsaganis, 2020; Perez \& Matsaganis, 2019).

Second, although more analytical effort is needed to fully back up such an argument, the comparison of the two cases may also serve as an example of a shift towards the principles of a so-called "pan-European" welfare state. Indeed, the European social policy agenda prioritises the establishment and extension of minimum income provisions to guard against poverty and social exclusion (Deeming, 2017).

Yet, it is highly questionable that there can be a "one-size-fits-all" solution for minimum income protection in Europe. Hence, we do not claim that the observed shift is a sign of convergence with the "ideotype" of a "pan-European" welfare state. In fact, someone may argue that the establishment of GMI schemes in the two case studies is illustrative of a convergence at a normative level, but not an operational one.

Commonalities in the developmental trajectories of the Greek and Cypriot GMI, as exemplified by the explicit reference to these schemes in international agreements and by the eventual adoption of similar policy interventions, offer nevertheless a basis for discussing the context and the conditions necessary for 
pursuing a higher degree of homogeneity in welfare state arrangements. For instance, differences, such as those related to the implementation of the two schemes examined here, highlight the persistence of an often deeply rooted - and hence quasi-inescapable - heterogeneity that dominates the welfare state universe.

The move towards welfare state homogeneity seems, however, to remain slow, unstable and largely dependent on endogenous idiosyncrasies (Natili \& Jessoula, 2019). These continue to affect and ultimately shape domestic policy outcomes, in a way that is difficult to deny and sometimes quite hard to alter.

Disclosure. There are no financial conflicts of interest to disclose.

Notes on contributors. Varvara Lalioti is a senior researcher in the field of social policy, who is also currently teaching at the Hellenic Open University. She holds a DPhil from the University of Oxford, with a specialization in social policy, as well as postgraduate and bachelor degrees in political economy, public policy, sociology and history from US and Greek universities. She has taught BA and MA courses at Panteion University of Social and Political Sciences, the University of Peloponnese and the Democritus University of Thrace and has extensive research experience in international, European and national programmes. Her main research interests include the design and evaluation of labour market policies and outcomes, social assistance policies and comparative social policy analysis.

Christos Koutsampelas is Assistant Professor in the Department of Social and Educational Policy of the University Peloponnese. His research focuses on identifying, measuring and explaining socio-economic inequalities and on how public policy might contribute to the reduction of inequalities in an efficient and sustainable way. His research has been published in peerreviewed academic journals such as Economics Letters, Education Economics, International Journal of Social Economics, International Journal of Educational Development and others.

\section{References}

Adnett, N., \& Hardy, S. (2005). The European social model: Modernization or evolution?. Cheltenham: Elgar.

Aguilar-Hendrickson, M., \& Arriba González de Durana, A. (2020). The politics of safety net reform in southern Europe during the great recession: Introduction to the regional issue. Social Policy \& Administration, 54(4), 533-538.

Aisen, A., \& Veiga, F. J. (2011). How does political instability affect economic growth? International Monetary Fund (International Monetary Fund, Working paper no. 11/12).

Atkinson, A. (1998). Poverty in Europe. Oxford: Blackwell.

Bahle, T., Hubl, V., \& Pfeifer, M. (2011). The last safety net. A handbook of minimum income protection in Europe. Bristol: Policy Press and Bristol University Press.

Cerna, L. (2013). The nature of policy change and implementation: A review of different theoretical approaches. Paris: OECD Publishing.

Christofides, L., \& Koutsampelas, C. (2019). The social protection system in Cyprus: Recent initiatives and labour market implications. Cyprus Economic Policy Review, 13(2), 3-47.

Chrysostomou, S., \& Andreou, S.N. (2017). Do low income Cypriots experience food stress? The cost of a healthy food basket relative to guaranteed minimum income in Nicosia, Cyprus. Nutrition and Dietetics, 74(2), 167-174.

Council of Europe: Commissioner for Human Rights (2016). Report by Nils Muiznieks following his visit to Cyprus from 7 to 11 December 2015, CommDH (2016)16. https://www.refworld.org/docid/572232044.html (accessed 27 March 2021).

Deeming, C. (2017). Defining minimum income (and living) standards in Europe: Methodological issues and policy debates. Social Policy \& Society, 16(1), 33-48.

Deeming, C. (2020). Minimum income standards and reference budgets: International and comparative policy perspectives. Bristol: Policy Press.

Dommen, E. (1980). Some distinguishing characteristics of island states. World Development, 8, 931-943.

European Commission (2017). Country report Cyprus 2017. Brussels: European Commission (European Commission Staff Working document).

European Commission (2018). Country report Cyprus 2018. European Commission Staff Working Document, Brussels.

European Commission (2019). Country report Cyprus 2019. Brussels: European Commission (European Commission Staff Working document).

Farnsworth K., \& Irving, Z. (Eds.) (2015). Social policy in times of austerity: Global economic crisis and the new politics of welfare. Bristol: Policy Press.

Farnsworth, K., \& Irving, Z. (2017). Crisis, austerity, competitiveness and growth: New pathologies of the welfare state. In D. Horsfall and J. Hudson (Eds.), Social policy in an era of competition: From global to local perspectives (pp. 187-199). Bristol: Policy Press. 
Ferrera, M. (Ed.). (2005). Welfare state reform in Southern Europe. Fighting poverty and social exclusion in Italy, Spain, Portugal and Greece. London: Routledge/EUI Studies in the Political Economy of Welfare.

Gal, J. (2010). Exploring the extended family of Mediterranean welfare states, or: Did Beveridge and Bismarck take a Mediterranean cruise together? In M. Ajzenstadt and J. Gal (Eds.), Children, gender and families in Mediterranean welfare states (pp. 77-101). New York: Springer.

Gavroglou, S. (2015). Minimum social income. EIEAD group of evaluation, fourth deliverable, comparative evaluation of the scheme. Athens: National Institute of Labour and Human Resources (in Greek).

Häusermann, S., Picot, G., \& Geering, D. (2013). Review article: Rethinking party politics and the welfare state - Recent advances in the literature. British Journal of Political Science, 43(1), 221-240.

Hinrichs, K. (2000). Elephants on the move-patterns of pension reform in OECD. European Review, 8(3), 353-378.

Hurwitz, L. (1973). Contemporary approaches to political stability. Comparative Politics, 5(3), 449-463.

Irving, Z. (2010). Curious cases: Small island states' exceptionalism and its contribution to comparative welfare theory. The Sociological Review, 58(2), 227-245.

Jessoula, M., Kubisa, J., Madama, I., \& Zielenska, M. (2014). Understanding convergence and divergence: Old and new cleavages in the politics of minimum income schemes in Italy and Poland. Journal of International and Comparative Social Policy, 30(2), 128-146.

Jessoula, M., \& Natili, M. (2020). Explaining Italian “exceptionalism” and its end: Minimum income from neglect to hyperpoliticization. Social Policy \& Administration, 54(4), 599-613.

Koutsampelas, C. (2016). The Cypriot GMI scheme and comparisons with other European countries. Cyprus Economic Policy Review, 10(1), 3-26.

Koutsampelas, C., Andreou, S. N., \& Tsolaki, E. (2019). ESPN thematic report on national strategies to fight homelessness and housing exclusion - Cyprus. European Social Policy Network (ESPN). Brussels: European Commission.

Koutsampelas, C., \& Pashardes, P. (2017). Social protection in Cyprus: Overview and challenges. University of Cyprus (Economic Policy Papers, Working paper no. 05-17).

Lalioti, V. (2016a). The curious case of the guaranteed minimum income (GMI): Highlighting "exceptionalism" in a southern European context. Journal of European Social Policy, 26(1), 80-93.

Lalioti, V. (2016b). Guaranteed minimum income "à la Grecque": The chronicle of a long-awaited scheme. Social Cohesion and Development, 11(2), 123-138.

Lalioti, V. (2020). Chapter 2: The genesis of comparative social policy. In C. Aspalter (Ed.), Ideal types in comparative social policy (pp. 17-40). London: Routledge.

Madama, I. (2010). Le politiche di assistenza sociale. Bologna: Il Mulino.

Marlier, E., \& Frazer, H. (2016). Minimum income schemes in Europe. European Social Policy Network (ESPN). Brussels: European Commission.

Marx I., \& Nelson K. (Eds.). (2013). Minimum income protection in flux. Basingstoke: Palgrave Macmillan.

Matsaganis, M. (2020). Safety nets in (the) crisis: The case of Greece in the 2010s. Social Policy \& Administration, 54(4), 587-598.

Matsaganis, M., Ferrera, M., Capucha, L., \& Moreno, L. (2003). Mending nets in the south: Anti-poverty policies in Greece, Italy, Portugal and Spain. Social Policy \& Administration, 37(6), 639-655.

Natili, M. (2018). The politics of minimum income. Explaining path departure and policy reversal in the age of austerity, Work and Welfare in Europe. Palgrave Macmillan.

Natili, M. (2020). Worlds of last-resort safety nets? A proposed typology of minimum income schemes in Europe. Journal of International and Comparative Social Policy, 36(1), 57-75.

Natili, M., \& Jessoula, M. (2019). Children against parents? The politics of intergenerational recalibration in Southern Europe. Social Policy \& Administration, 53(3), 343-356.

Natili, M., Jessoula, M., Madama, I., \& Matsaganis, M. (2019). The right(s) and minimum incomes in hard times: Southern and Eastern Europe compared. European Societies, 21(1), 33-51.

Nelson, K. (2013). Social Assistance and EU Poverty Thresholds 1990-2008. Are European Welfare Systems Providing Just and Fair Protection Against Low Income? European Sociological Review 29(2), 386-401.

Noël, A. (2019). The politics of minimum income protection in OECD countries. Journal of Social Policy, 48(2), $227-247$.

Pal, L. (2014). Beyond policy analysis - Public issue management in turbulent times (fifth Edn.). Toronto: Nelson Education.

Pashardes, P. (2009). Minimum income schemes: Cyprus. Network of Independent Experts on Social Inclusion. Brussels: European Commission.

Pashardes, P., \& Koutsampelas, C. (2015). Minimum income schemes: Cyprus. European Social Policy Network (ESPN). Brussels: European Commission.

Pashardes, P., \& Koutsampelas, C. (2016). European Semester Report: Cyprus. European Social Policy Network (ESPN). Brussels: European Commission, unpublished manuscript.

Pashardes, P., Koutsampelas, C., \& Polycarpou, A. (2013). Impact assessment of alternative GMI scenarios. Report prepared for the ILO, Unpublished manuscript. 
Pashardes, P., \& Polycarpou, A. (2011). Poverty and labour market participation of public assistance recipients in Cyprus. Cyprus Economic Policy Review, 5(1), 23-42.

Perez, S.A., \& Matsaganis, M. (2019). Export or perish: Can internal devaluation create enough good jobs in southern Europe? South European Society and Politics, 24(2), 259-285.

Rapanos, V.T., \& Kaplanoglou, G. (2014). Governance, growth and the recent economic crisis: The case of Cyprus. Cyprus Economic Policy Review, 8(1), 3-24.

Sakellaropoulos, T., Lalioti, V., \& Kourachanis, N. (2019). The social impact of the "social solidarity income" in Greece: A qualitative interpretation. Social Cohesion and Development, 14(1), 5-20.

Satsias N. (2014). Country Report Cyprus. European Minimum Income Network, Analysis and Road Map for Accessible Minimum Income Schemes in EU Member States.

Shekeris, A. (1998). The Cypriot welfare state: Contradiction and crisis? The Cyprus Review, 10(2), 113-134.

Sotiropoulos, D. (2004). Democratization, administrative reform and the state in Greece, Italy, Portugal and Spain: Is there a "model" of South European Bureaucracy? The Hellenic Observatory, The London School of Economics and Political Science, London.

Soumeli, E. (2014). Cyprus: Guaranteed minimum income: Eurofound.

Starke, P., Kaasch, A., \& Van Hooren, F. (2013). The welfare state as crisis manager. Explaining the diversity of policy responses to economic crisis. Basingstoke: Palgrave MacMillan.

Stylianides, T. (2019). Establishment and operation of the Welfare Benefit Management Service (YDEP of the Ministry of Labour, Welfare and Social Insurance). Case study of Cypriot ESF project under the study "Progress Assessment of the ESF Support to Public Administration". Luxembourg: Publications Office of the European Union.

Svensson, M., Urinboyev, R., \& Åström, K. (2012). Welfare as a means for political stability: A law and society analysis. European Journal of Social Security, 14(2), 64-85.

Van Kersbergen, K., \& Vis, B. (2014). Comparative welfare state politics: Development, opportunities and reform: New York: Cambridge University Press.

Venieris, D. (1997). Dimensions of social policy in Greece. In M. Rhodes (Ed.), Southern European welfare states (pp. 260-269). London: Frank Cass.

World Bank (2015). Greece: Guaranteed minimum income program pilot, reimbursable advisory services agreement of 31 October 2013, final output 4, process evaluation paper.

World Bank (2017). World development report. Chapter 2, “Enhancing governance for development: Why policies fail,” pp. 5176.

World Bank (2019). A quantitative evaluation of the Greek social solidarity income. Washington, DC: World Bank Group (World Bank Group, Working paper no. 133962).

Ziomas, D., Capella, A., \& Konstantinidou, K. (2017). The national roll-out of the social solidarity income scheme in Greece. ESPN. Brussels: European Commission. 


\section{APPENDIX}

Table A1. GMI coverage in Cyprus and Greece (2017).

\begin{tabular}{lcc}
\hline & Greece & Cyprus \\
\hline Number of beneficiaries & $700,000^{\mathrm{a}}$ & $54,720^{\mathrm{b}}$ \\
\hline Number of persons in severe poverty ${ }^{\mathrm{b}}$ & 984,000 & 23,000 \\
\hline Number of persons in poverty ${ }^{c}$ & $2,151,000$ & 134,000 \\
\hline (a) $/(\mathrm{b})$ & 0.71 & 2.38 \\
\hline (a) $/(\mathrm{c})$ & 0.32 & 0.41 \\
\hline
\end{tabular}

${ }^{\mathrm{a}}$ Figure found in Table 3 in Natili (2020).

${ }^{\mathrm{b}}$ The number of recipient units (i.e. 32,000 ) was multiplied with the average size of the recipient unit (1.71) derived from (European Commission, 2018).

${ }^{c}$ Figures retrieved from Eurostat (ilc_li02) setting the poverty threshold at 40\% (severe poverty) and 60\% (poverty).

Table A2. Minimum income (MI) adequacy in Cyprus and Greece (2014-2018).

\begin{tabular}{|c|c|c|c|c|c|c|c|c|}
\hline & \multicolumn{8}{|c|}{ Median equivalised net income per annum $(€)$} \\
\hline & 2014 & 2015 & 2016 & & 2017 & & 2018 & \\
\hline Greece & 7,680 & 7,520 & 7,500 & & 7,600 & & 7,863 & \\
\hline \multirow[t]{3}{*}{ Cyprus } & 14,400 & 13,793 & 14,020 & & 14,497 & & 15,336 & \\
\hline & \multicolumn{8}{|c|}{ Basic annual GMI amount for a single adult $(€)$} \\
\hline & 2014 & 2015 & 2016 & & 2017 & & 2018 & \\
\hline Greece & 2,400 & 2,400 & 2,400 & & 2,400 & & 2,400 & \\
\hline \multirow[t]{3}{*}{ Cyprus } & 5,760 & 5,760 & 5,760 & & 5,760 & & 5,760 & \\
\hline & \multicolumn{8}{|c|}{ MI adequacy } \\
\hline & 2014 & 2015 & 2016 & 2017 & & 2018 & & $2014-2018^{a}$ \\
\hline Greece & 31.3 & 31.9 & 32.0 & 31.6 & & 30.5 & & 31.5 \\
\hline Cyprus & 40.0 & 41.8 & 41.1 & 39.7 & & 37.6 & & 40.0 \\
\hline
\end{tabular}

Notes: Definition of minimum adequacy is based on Nelson (2013); minimum income benefits for a given household are divided by the country's equivalised median income and then multiplied by 100 (Nelson, 2013, p. 391).

a 2014-2018 averages.

Source: Median equivalised net income is provided by Eurostat.

Cite this article: Lalioti, V. and Koutsampelas, C. (2021). The Greek vs. the Cypriot guaranteed minimum income schemes: an exploratory comparative analysis. Journal of International and Comparative Social Policy 37: 226-242. https://doi.org/10.1017/ ics. 2021.5 